\title{
Pengaruh Variabel Keuangan dan Non Keuangan terhadap Underpricing pada Perusahaan yang Melakukan Initial Public Offering (IPO) di Bursa Efek Indonesia
}

\author{
Martha Rianty $\mathbf{N}^{1}$ dan Dwi Riana ${ }^{2}$ \\ 1-2Jurusan Akuntansi, Universitas Tridinanti Palembang \\ Email:Rianty533@gmail.com \\ Email:dwiriana@univ-tridinanti.ac.id
}

\begin{abstract}
Underpricing is a phenomenon in initial public offering that often occurs in the capital market and has been proven by research in many countries. This study aims to analyze financial and non-financial factors that effect underpricing. This research is done in Indonesia stock exchange specifically on those companies that are going on initial public offering in 2010-2015. Underpricing is measured using intial abnormal return which is the dependent variable of this study. Meanwhile the independent variables are financial leverage (financial variable), auditor reputation, underwriter reputation, (non-financial variables). 114 companies are selected as the sample through purposive sampling method. Logistic regression model is used to test the relationship between the variables. The results show that the reputation of underwriter and auditor are significant and positive in affecting the underpricing. Meanwhile, financial leverage are found to be insignificant in affecting the underpricing.

Keywords: financial leverage, auditor reputation, underwriter reputation, underpricing, initial public offering
\end{abstract}

\begin{abstract}
Abstrak
Penelitian bertujuan untuk menguji pengaruh variabel keuangan leverage, dan) dan variabel non keuangan (reputasi underwriter dan reputasi auditor,) terhadap underpricing. Berdasarkan metode purposive sampling, jumlah sampel dalam penelitian ini adalah 114 perusahaan go public dari tahun 2010 sampai tahun 2015. Metode analisa data menggunakan regresi logistic. Hasil analisis regresi logistik pengaruh variabel keuangan terhadap underpricing,variabel keuangan yang berpengaruh signifikan adalah reputasi underwriter dan reputasi auditor. Variabel DER perusahaan tidak berpengaruh signifikan terhadap underpricing. Hasil ini mendukung teori yang menyatakan reputasi penjamin emisi dan reputasi auditor dapat dipakai sebagai sinyal untuk mengurangi tingkat ketidakpastian yang tidak dapat diungkapkan oleh informasi yang terdapat dalam prospektus dan memberi sinyal bahwa informasi privat dari emiten mengenai prospek perusahaan dimasa datang tidak menyesatkan.

Kata Kunci : IPO, Leverage, Auditor Reputation, Underwriter Reputation, Underpricing
\end{abstract}

\section{Pendahuluan}

Salah satu cara bagi perusahaan untuk menambah modal adalah dengan menjual saham ke publik. Bagi investor yang akan melakukan investasi dengan membeli saham IPO, pasti berharap akan adanya keuntungan atas investasi tersebut, baik jangka pendek maupun jangka panjang, tergantung tujuan investasinya. Memang seperti yang dikatakan oleh Thornton, Michael, George.(2009) bahwa secara historis umumnya perusahaan yang melakukan IPO selalu mengalami underpicing. Beatty (1989) menyatakan bahwa asimetri informasi dapat menyebabkan underpricing pada saat IPO. 
Asimetri bisa terjadi antara emiten, underwriter, dan investor. Asimetri informasi mengasumsikan salah satu dari ketiga pihak tersebut memiliki lebih banyak informasi dibandingkan pihak lainnya.

\begin{tabular}{|c|c|c|c|c|c|}
\hline $\begin{array}{l}\text { Perkembangan } \\
\text { IPO di } \\
\text { Indonesia } \\
\text { Tahun 2010- } \\
2015 \text { Tahun }\end{array}$ & Underpricing & $\begin{array}{c}\text { Underpricing } \\
\text { Terendah }\end{array}$ & $\begin{array}{c}\text { Underpricing } \\
\text { Tertinggi }\end{array}$ & Overpricing & Tetap \\
\hline 2010 & 22 & $1,39 \%$ & $70,00 \%$ & 1 & 0 \\
\hline 2011 & 17 & $2,00 \%$ & $66,67 \%$ & 7 & 1 \\
\hline 2012 & 21 & $1,32 \%$ & $69,52 \%$ & 1 & 1 \\
\hline 2013 & 22 & $1,08 \%$ & $69,44 \%$ & 7 & 2 \\
\hline 2014 & 21 & $0,69 \%$ & $70,00 \%$ & 2 & 1 \\
\hline 2015 & 16 & $1,32 \%$ & $69,57 \%$ & 1 & 1 \\
\hline
\end{tabular}

Mengenai faktor-faktor yang mempengaruhi underpricing telah dilakukan banyak penelitian, dan penelitian tersebut telah menemukan bahwa underpricing lebih tinggi jika: umur perusahaan lebih muda (Ritter, 1984), kualitas underwriter rendah (Carter \& Manaster, 1990), kualitas auditor rendah (Beatty, 1989), dan penelitian yang dilakukan oleh Guo (2005) yang menemukan bahwa underpricing akan lebih tinggi jika pengeluaran Research and Development perusahaan kecil (dalam Dimovski \& Brooks, 2008). Martani dan Syahroza (2012) menghasilkan bahwa variabel reputasi auditor tidak berpengaruh signifikan positif terhadap tingkat underpricing.

Beberapa penelitian juga secara khusus menguji hipotesa-hipotesa di atas di pasar modal negara berkembang seperti China (Su dan Fleisher:1997), India ( Ghosh:2000), Brazil, Chile dan Mexico (Aggarwal dkk:1993), Malaysia, Singapura dan Hongkong (Dawson:1987, Blake dan Freris:1997, Shamser, Annuar, dan Mohamed (1993). Secara umum hasilnya tidak konsisten, beberapa faktor ternyata tidak terbukti mendorong terjadinya underpricing, sebaliknya faktor tertentu ternyata terbukti.Ditambah lagi dengan karakteristik regulasi yang berlaku di masing-masing pasar modal yang menyulitkan pengambilan kesimpulan antar satu pasar modal dengan yang lainnya.Namun keseluruhan penelitian masih belum ada yang dapat menerangkan fenomena ini secara integratif yang ditunjukkan dengan expalanatory power yang tinggi dari model yang ditawarkan. Secara umum penelitian masih menghasilkan kesimpulan parsial yang menguji satu atau lebih faktor saja. Kemungkinan besar dengan sebaran data cross section maka heteroskedastisitas menjadi masalah sehingga ketika dilakukan pengujian multivariate menghasilkan tingkat signifikansi koefisien parameter yang rendah.

Sampel yang digunakan pada penelitian ini adalah semua jenis perusahaan yang terdaftar di Bursa Efek Indonesia, yang melakukan IPO pada periode tahun 2010 sampai dengan 2015. Variabel keuangan yang digunakan dalam penelitian ini adalah dan leverage, sedangkan variabel non keuangan yang digunakan dalam penelitian ini adalah ukuran perusahaan, reputasi underwriter, reputasi auditor, dan umur perusahaan. Penulis tertarik untuk meneliti dengan mengadakan evaluasi dan modifikasi terhadap penelitian-penelitian sebelumnya yang menunjukkan ketidakkonsistenan hasil penelitian, dengan demikian judul penelitian ini adalah "Pengaruh Variabel Keuangan dan Non Keuangan Terhadap Underpricing Pada Perusahaan Yang Melakukan Initial 
Public Offering (IPO) di Bursa Efek Indonesia"

\section{Landasan Teori Agency Theory (Teori Agensi)}

Teori yang dapat digunakan untuk menjelaskan penyebab fenomena underpricing pada saat IPO adalah agency theory. Brigham (2014) menyatakan bahwa permasalahan agen muncul karena adanya konflik kepentingan antara agen (manajer) dan pemegang saham atau antara agen (manajer) dengan kreditor (pemberi hutang). Permasalahan yang timbul pada agency theory adalah informasi yang tidak lengkap, yaitu ketika tidak semua keadaan diketahui oleh kedua belah pihak. Akibatnya konsekuensi tertentu tidak dipertimbangkan oleh masing-masing pihak.

\section{Signaling Theory}

Signalling Theory atau teori sinyal dikembangkan oleh (Ross, 1977), menyatakan bahwa pihak eksekutif perusahaan memiliki informasi lebih baik mengenai perusahaannya akan terdorong untuk menyampaikan informasi tersebut kepada calon investor agar harga saham perusahaannya meningkat. Welch (1989) menyatakan bahwa underpricing pada IPO merupakan suatu mekanisme untuk memberikan signal tentang kualitas perusahaan. Oleh karena itu perusahaan yang memiliki kualitas baik melakukan underpricing pada saat IPO. Ljungqvist (2001)menyatakan bahwa jika perusahaan memiliki informasi yang lebih baik tentangnilai sekarang (present value) dan risiko dari aliran kas perusahaan di masa depandi bandingkan dengan informasi yang dimiliki investor, underpricing dapat dijadikan suatu jalan untuk meyakinkan investor tentang nilai perusahaan yangsebenarnya.

\section{Hypothesis Asymetric Information}

Suatu penjelasan mengenai fenomena underpricing adalah adanya asimetri informasi. Menurut Beatty (1989) asimetri informasi dapat terjadi antara perusahaan emiten dengan underwriter (Model Baron) atau antara informed investor dengan uninformed investor (Model Rock). Pada model Baron (1982) penjamin emisi (underwriter) dianggap memiliki informasi tentang pasar yang lebih lengkap daripada emiten sedangkan terhadap calon investor, penjamin emisi memiliki informasi yang lebih lengkap tentang kondisi emiten. Semakin besar asimetri informasi yang terjadi maka semakin besar risiko yang dihadapi oleh investor, dan semakin tinggi initial return yang diharapkan dari harga saham.

\section{Penawaran Umum Perdana (Initial Public Offering)}

Perusahaan yang membutuhkan dana dapat melakukan penerbitan surat berharga seperti saham (stock), obligasi (bond), dan sekuritas lainnya. Surat berharga yang baru dijual berupa penawaran perdana ke publik (Initial Public Offering atau IPO) atau tambahan surat berharga baru jika perusahaan sudah gopublic. Dalam UndangUndang Pasar Modal selanjutnya disebut UUPM, Pasal 1 memuat definisi penawaran umum (public offering), yaitu kegiatan penawaran efek yang dilakukan oleh emiten untuk menjual efek kepada masyarakat berdasarkan tata cara yang diatur dalam undang-undang ini dan peraturan pelaksananya. Setelah saham dijual ke pasar perdana kemudian saham tersebut didaftarkan di pasar sekunder (listing). Dengan mendaftarkan saham tersebut di bursa, saham tersebut mulai diperdagangkan di bursa efek bersama dengan efek yang lain. 


\section{Underpricing}

Istilah underpricing digunakan untuk menggambarkan perbedaan antara harga penawaran saham di pasar primer dan harga saham di pasar sekunder. Menurut (Beatty, 1989), pada hari pertama underpricing merupakan fenomena yang sering dijumpai dalam IPO. Ada kecenderungan bahwa harga penawaran di pasar perdana selalu lebih rendah dibandingkan dengan harga penutupan pada hari pertama diperdagangkan di pasar sekunder. Di Amerika Serikat, beberapa studi, termasuk Ritter $(1984,1991)$, telah mengkonfirmasi fenomena IPO underpricing. Sejak tahun 1960, harga diskon telah ratarata sekitar 19\%, tetapi dengan fluktuasi yang cukup besar, rata-rata 21\% di1960, 12\% pada tahun 1970, 16\% pada tahun 1980, 21\% pada tahun 1990 dan $40 \%$ di4 tahun sejak tahun 2000 (Ljungqvist, 2005). Tingkat underpricing bahkan lebih kuat pada akhir 1990an dan di tahun-tahun pertama sejak tahun 2000, bertepatan dengan booming IPO Internet.Loughran, Ritter dan Rydqvist (1994) mengkonfirmasi fenomena underpricing ini dengan meninjau lebih dari 30 studi di 25 negara, dengan underpricing lebih tinggi dinegara berkembang daripada pasar negara maju. IPO Cina juga menunjukkan sebuah underpricing 948,6\% (Su \& Fleisher, 1999.)

\section{Informasi Keuangan dan Non Keuangan}

Berdasarkan Peraturan Bappepam Nomor IX.C.2 tentang Pedoman Mengenai Bentuk dan Isi Prospektus Dalam Rangka Penawaran Umum maka investor membutuhkan adanya informasi atau prospektus dari perusahaan penerbit saham baik berupa informasi keuangan maupun non keuangan untuk memperoleh Initial Return. Informasi keuangan sendiri yaitu berupa informasi yang berasal dari data keuangan perusahaan seperti laporan keuangan perusahaan.Dari laporan keuangan tersebut dilakukan analisis rasio keuangan yang selalu digunakan untuk mengetahui kesehatan keuangan dan kemajuan perusahaan.

\section{Financial Leverage (DER)}

Rasio yang dikenal pula dengan sebutan DER (Debt To Equity Ratio. Leverage ratio (rasio solvabilitas) mengukur besarnya hutang yang digunakan untuk membiayai kegiatan usaha jika dibandingkan dengan modal sendiri, serta besar hutang tersebut dialokasikan untuk membiayai aktivanya (Kasmir, 2014:113). Menurut Kasmir (2014:114), profitabilitas menunjukkan ukuran tingkat efektivitas manajemen perusahaan melalui laba hasil penjualan atau pendapatan investasi. Untuk mengukur Financial leverage indikator yang digunakan adalah total debt dan total shareholder equity. Financial leverage dapat diukur dengan rumus sebagai berikut:

$$
D E R=\frac{\text { Total Debt }}{\text { Total Share holder Equity }} \times 100 \%
$$

\section{Reputasi Underwriter (UDR)}

Dimovski \& Brooks (2008) mengemukakan bahwa reputasi penjamin emisi (underwriter) berpengaruh negatif terhadap underpricing.Penjamin emisi atau disebut underwriter, berfungsi dalam melakukan penjaminan atas penawaran umum suatu saham atau obligasi untuk pertama kalinya yaitu pada saat go public. Fungsi underwriter pada saat IPO yaitu menjamin terjualnya saham sesuai dengan tipe penjaminan yang 
disepakati dan menentukan harga penawaran yang tepat bersama-sama dengan emiten.Mereka juga memberi nasehat tentang hal-hal yang perlu diperhatikan emiten serta bagaimana dan kapan saat yang tepat melakukan penawaran.(Kunz, 1994).

\section{Reputasi Auditor (AUD)}

Menurut Balvers, Mc Donald, dan Miller (1988) keberadaan auditor melayani dua tujuan, yaitu untuk mengurangi ketidakpastian dalam laporan keuangan, dan untuk memberikan signal tentang reputasi underwriter. Auditor yang mempunyai reputasi yang tinggi, akan mempertahankan reputasinya dengan memberikan kualitas yang baik terhadap hasil auditannya. Dengan menggunakan jasa auditor yang professional akan mengurangi kesempatan emiten untuk berlaku curang dalam menyajikan informasi yang kurang akurat sehingga penggunaan auditor yang professional dapat digunakan sebagai petunjuk kualitas perusahaan.

Variabel ini menggunakan variabel dummy, dimana nilai 1 diberikan kepada perusahaan yang menggunakan jasa auditor yang memiliki reputasi baik (The Big Four), dan nilai 0 untuk perusahaan yang tidak menggunakan jasa auditor dalam kategori The Big Four.

\section{Kerangka Penelitian}

Kerangka konseptual dari penelitian dapat digambarkan sebagai berikut:

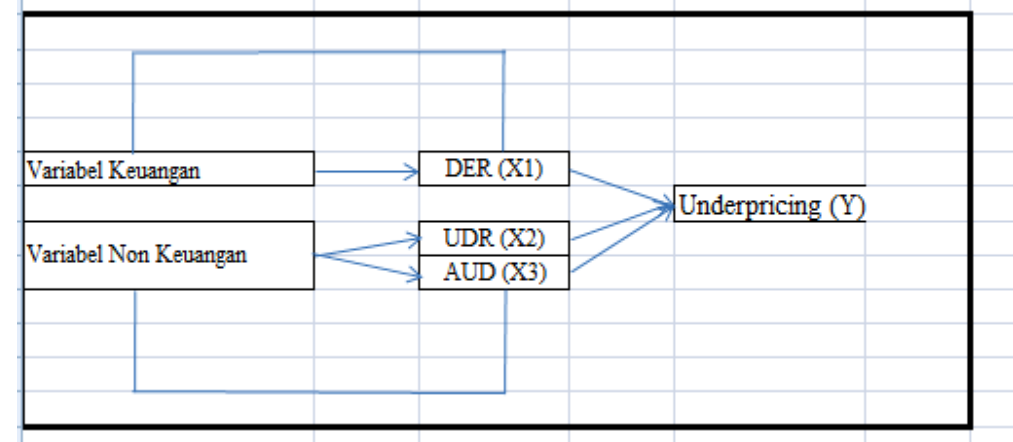

Gambar 1

Kerangka Penelitian

\section{Hipotesis Penelitian}

Berdasarkan pada latar belakang di atas perumusan masalah, landasan teori serta kerangka berpikir di atas, maka hipotesis yang diajukan dalam penelitian ini adalah :

$\mathrm{H}_{1}$ : DER berpengaruh negatif terhadap underpricing.

$\mathrm{H}_{2}$ : Reputasi underwriter berpengaruh positif terhadap underpricing

$\mathrm{H}_{3}$ : Reputasi auditor berpengaruh positif terhadap underpricing.

\section{Metode Penelitian}

Ruang lingkup penelitian ini terdiri dari variabel independen variabel independen (X) yaitu DER $\left(\mathrm{X}_{1}\right)$, Reputasi Underwriter $\left(\mathrm{X}_{2}\right)$, Reputasi Auditor $\left(\mathrm{X}_{3}\right)$ sedangkan variabel dependen (Y) yaitu Underpricing. Penulis akan melakukan pengujian secara parsial dan simultan, sebelum melakukan pengujian tersebut Penulis akan mengukur variabelvariabel independen dan dependen dengan proksi yang telah ditentukan.

Data sekunder dalam penelitian ini berupa, financial report perusahaan yang 
terdaftar di BEI, daftar 4 besar Kantor Akuntan Publik (KAP) di Indonesia, liabilities, profit after tax, dan daftar nama underwriter dan akuntan publik yang mengaudit laporan keuangan, daftar nama reputasi underwriter perusahaan-perusahaan yang terdaftar di Bursa Efek Indonesia (BEI) tahun 2010-2015. Populasi dalam penelitian ini adalah selutuh perusahaan go public yang telah terdaftar di Bursa Efek Indonesia yang melakukan penawaran umum perdana atau IPO 2010 sampai dengan periode pengamatan tahun 2015.

Tabel 2 Rincian Jumlah Sampel

\begin{tabular}{lc}
\hline \multicolumn{1}{c}{ Keterangan } & $\begin{array}{c}\text { Jumlah } \\
\text { Perusahaan }\end{array}$ \\
\hline Perusahaan yang melakukan IPO tahun 2010 & 23 \\
Perusahaan yang melakukan IPO tahun 2011 & 26 \\
Perusahaan yang melakukan IPO tahun 2012 & 22 \\
Perusahaan yang melakukan IPO tahun 2013 & 30 \\
Perusahaan yang melakukan IPO tahun 2014 & 22 \\
Perusahaan yang melakukan IPO tahun 2015 & 17 \\
Perusahaan yang menyajikan LK tidak dalam rupiah & $(10)$ \\
Perusahaan yang harga sahamnya tetap & $(17)$ \\
Perusahaan yang mengalami rugi & $(6)$ \\
Jumlah sampel yang dipakai dalam penelitian & 114 \\
\hline \multicolumn{2}{c}{ Sumber : Factbook 2011-2016 }
\end{tabular}

Model yang digunakan untuk melihat pengaruh variabel independen (X) yaitu DER, Reputasi Underwriter (UDR) dan Reputasi Auditor (AUD) terhadap variabel dependen (Y) yaitu Underpricing (UND) dengan regresi logistik (logistic regression). Persamaan regresi logistik sebagai berikut:

$$
\operatorname{Ln} \frac{\mathrm{P}}{1-\mathrm{p}}=\mathrm{UNDno}_{\mathrm{t}}=\beta_{0}+\beta_{2} \text { DERni }_{\mathrm{t}}+\beta_{3} \mathrm{UDRno}_{\mathrm{t}}+\beta 4 \text { AUDnit }_{\mathrm{t}}+\varepsilon
$$

Metode analisis data dalam penelitian ini adalah dengan menggunakan teknik analisis kuantitatif. Analisis kuantitatif dilakukan dengan cara menganalisis suatu permasalahan yang diwujudkan dengan kuantitatif. Analisis kuantitatif dalam penelitian sehingga menghasilkan informasi yang dibutuhkan dalam analisis.

Alat analisis yang digunakan dalam penelitian ini adalah analisis regresi logistic (logistic regression) dengan bantuan program statstika.Alasan penggunaan alat analisis regresi logistic (logistic regression) adalah karena variabel bersifat dummy. Hal ini dapat dianalisis dengan regresi logistic (logistic regression) karena tidak perlu asumsi normalitas data pada variabel bebasnya (Ghozali,2011:133). 
Tabel 3. Descriptive Statistics

\begin{tabular}{|c|c|c|c|c|c|}
\hline & $\mathrm{N}$ & Minimum & Maximum & Mean & Std. Deviation \\
\hline & 1 & .001 & 8459.594 & 358.57394 & 963.677986 \\
\hline \multirow[t]{3}{*}{ DER } & 1 & & & & \\
\hline & 4 & & & & \\
\hline & 1 & 0 & 1 & .32 & .467 \\
\hline \multirow[t]{3}{*}{ Underwriter } & 1 & & & & \\
\hline & 4 & & & & \\
\hline & 1 & 0 & 1 & .27 & .447 \\
\hline \multirow[t]{3}{*}{ Auditor } & 1 & & & & \\
\hline & 4 & & & & \\
\hline & 1 & 0 & 1 & .61 & .489 \\
\hline \multirow[t]{2}{*}{ Underpricing } & 1 & & & & \\
\hline & 4 & & & & \\
\hline \multirow{3}{*}{$\begin{array}{l}\text { Valid N } \\
\text { (listwise) }\end{array}$} & 1 & & & & \\
\hline & 1 & & & & \\
\hline & 4 & & & & \\
\hline
\end{tabular}

Tabel 4. Nilai VIF Uji Multikolinieritas Coefficients ${ }^{a}$

\begin{tabular}{|c|c|c|c|c|c|c|c|c|}
\hline \multicolumn{9}{|c|}{ Coefticlents $^{\mathrm{a}}$} \\
\hline & \multirow{2}{*}{ Model } & \multicolumn{2}{|c|}{$\begin{array}{c}\text { Unstandardized } \\
\text { Coefficients }\end{array}$} & $\begin{array}{l}\text { Standardized } \\
\text { Coefficients }\end{array}$ & \multirow[t]{2}{*}{$\mathrm{T}$} & \multirow{2}{*}{ Sig. } & \multicolumn{2}{|c|}{ Collinearity Statistics } \\
\hline & & $\mathrm{B}$ & Std. Error & Beta & & & Tolerance & VIF \\
\hline \multirow{4}{*}{1} & (Constant) & -1.090 & 1.008 & & -1.082 & 281 & & \\
\hline & DER & .000 & .000 & .144 & 1.599 & .112 & .940 & 1.064 \\
\hline & Underwriter & -.117 & .096 & -.107 & -1.214 & .227 & .975 & 1.026 \\
\hline & Auditor & -.180 & .106 & -.162 & -1.694 & .093 & .839 & 1.192 \\
\hline
\end{tabular}

a. Dependent Variable: Underpricing

Interpretasi dari tabel di atas yaitu:

a) Konstanta (Koefisien a) : Nilai konstanta sebesar -1.090 berarti apabila variabel bebas yang terdiri dari $\mathrm{X}_{1}, \mathrm{X}_{2}, \mathrm{X}_{3}$ nilainya nol maka tingkat underpricing akan turun sebesar 1.090

b) Koefisien DER ( $\beta 2)$ : Nilai koefisien regresi untuk variabel DER yang bernilai 0,000 berarti apabila DER naik sebesar 1 satuan, maka tingkat underpricing akan naik sebesar 0,00 persen

c) Koefisien Reputasi Underwriter ( $\beta 3)$ : Nilai koefisien regresi untuk variabel underwriter yang bernilai $-0,117$ berarti apabila reputasi underwriter naik sebesar 1 satuan, maka tingkat underpricing akan menurun sebesar $0,117 \%$ dengan asumsi semua variabel independen lain dalam kondisi stabil, sehingga perusahaan yang ingin menekan tingkat underpricing disarankan memakai underwriter yang berpengalaman.

d) Koefisien Reputasi Auditor $\left(\beta_{4}\right)$ : Nilai koefisien variabel reputasi auditor yang bernilai - 0,180 berarti apabila reputasi auditor naik sebesar 1 satuan maka tingkat underpricing akan menurun sebesar $0,180 \%$ dengan asumsi semua variabel independen lain dalam kondisi stabil. Pengaruh negatif ini akan membuat 
perusahaan lebih menggunakan jasa auditor yang tergolong The Big Four agar tingkat underpricing dapat menjadi semakin kecil.

Hasil di atas menunjukkan bahwa nilai VIF masing-masing variabel bebas dibawah 10, yakni DER $\left(\mathrm{X}_{1}\right)=1,064$, Underwriter $\left(\mathrm{X}_{2}\right)=1,026$, Auditor $\left(\mathrm{X}_{3}\right)=1,192$. Berdasarkan hasil tersebut dapat disimpulkan bahwa tidak terdapat multikolinieritas antar variabel bebas dalam model.

\section{Hasil dan Pembahasan \\ Pengaruh Financial Leverge Terhadap Underpricing}

Hipotesis kedua( $\left.\mathrm{H}_{2}\right)$ yang menyatakan ada pengaruh DER terhadap besarnya tingkat underpricing tidak dapat diterima. Temuan ini mendukung hasil penelitian Kwan (2013), Dominique dan Tiffany (2013), dan tidak mendukung penelitian Saikat dan Vijaya (2010) dan penelitian Chiraphadhanakul dan Gunawarna (2005) yang menyatakan bahwa DER berpengaruh signifikan terhadap underpricing. Sementara teori menyatakan bahwa Leverage yang tinggi menunjukkan risiko finansial atau risiko kegagalan perusahaan untuk mengembalikan pinjaman akan semakin tinggi, dan sebaliknya. Oleh karena semakin tinggi leverage suatu perusahaan, maka underpricingnya semakin besar.

Alasan mengapa DER tidak berpengaruh signifikan terhadap underpricing adalah karena sampel dalam penelitian ini terdiri dari berbagai jenis industri termasuk industri perbankan yang memiliki karakteristik berbeda dalam laporan keuangannya sebagaimana diungkapkan dalam Pernyataan Standar Akuntansi Keuangan (PSAK) No. 31: Akuntansi Perbankan (Revisi 2000) bahwa laporan akuntansi dan laporan keuangan bank berbeda dengan jenis usaha lainnya. Kegiatan utama bank adalah menghimpun dana dari masyarakat dan menyalurkannya kembali kepada masyarakat. Dana yang dihimpun dari masyarakat tersebut merupakan kewajiban bagi bank dan dicatat sebagai utang. Oleh karena saldo utang yang besar pada neraca bank maka financial leverage yang terdapat pada industri perbankan berbeda secara signifikan dengan industri lainnya.

Dapat dikatakan juga bahwa hasil penelitian ini menyimpang dari kajian teori agensi yang menjelaskan bahwa leverage berpengaruh negatif terhadap underpricing. Hal tersebut dapat dibuktikan melalui nilai DER yang rendah sedangkan nilai underpricing juga rendah. Dengan demikian dapat diketahui bahwa adanya leverage tinggi tidak menjamin bahwa underpricing menjadi rendah. Besarnya leverage perusahaan akan menyebabkan perusahaan meningkatkan kualitas pelaporan keuangan dengan tujuan untuk mempertahankan kinerja yang baik di mata investor dan auditor namun tidak semua perusahaan mampu melakukan aktivitas ini karena sangat tergantung pada kredibilitas perusahaan. DER yang tinggi juga mencerminkan resiko perusahaan yang relatif tinggi sehingga mengakibatkan ketidakpastian harga saham dan berdampak pada return saham yang nantinya akan diterima investor, akibatnya investor cenderung menghindari saham-saham yang memiliki DER tinggi.

\section{Pengaruh Reputasi Underwriter Terhadap Underpricing}

Variabel non keuangan reputasi underwriter terbukti berpengaruh signifikan positif pada tingkat underpricing, artinya semakin tinggi reputasi underwriter maka tingkat underpricing akan semakin tinggi pula. Temuan ini sejalan dengan penelitian 
Sharma dan Seraphim (2010), Dimovski \& Brooks (2008) dan How, Izan, dan Gary (1995) namun tidak sejalan dengan penelitian Jhonson (2011), Balvers, Mc.Donald, dan Miller (1998) yang menyatakan bahwa reputasi underwriter tidak berpengaruh signifikan terhadap underpricing.

Reputasi penjamin emisi (underwriter) didefinisikan sebagai skala kualitas underwriter dalam menawarkan saham emiten.Ini berarti jumlah nilai yang dijamin menunjukkan kemampuan penjamin emisi untuk menanggung kerugian jika ternyata saham yang dijamin tidak laku terjual.Oleh karena besarnya nilai yang dijamin menunjukkan reputasi penjamin emisi, maka penjamin emisi yang reputasinya rendah, tentu hanya dapat menjamin dalam jumlah kecil. Lain halnya dengan penjamin emisi yang memiliki reputasi tinggi, tentu ia akan berani melakukan penjaminan dalam jumlah yang besar. Akibatnya, bagi penjamin emisi yang belum memiliki reputasi tentunya akan sangat hati-hati untuk menghindari risiko tersebut dengan cara menekan harga serendah mungkin. Berbeda dengan penjamin yang memiliki reputasi tinggi, mereka akan berani memberikan harga yang tinggi pula sebagai konsekuensi dan kualitas penjaminanya. Hal ini terbukti dengan berpengaruhnya reputasi underwriter terhadap underpricing dalam penelitian ini.

Implikasi dari hasil penelitian pada konteks ini membuktikan bahwa Underwriter yang bereputasi tinggi berani memberikan harga yang tinggi sebagai kosekuensi dari penjaminannya, tingkat underpricing rendah.Sebanyak 36 perusahaan yang IPO dari tahun 2010-2015 dalam penelitian ini menggunakan underwriter yang bereputasi tinggi. Pada penelitian ini, dapat dilihat bahwa perusahaan-perusahaan besar seperti MBSS (Mitrabahtera Segara Sejati Tbk) yang bergerak di bidang pelayaran, angkutan laut, baik barang maupun penumpang, pengangkutan minyak, penyewaan kapal laut, perwakilan pelayaran dari perusahaan pelayaran baik dlaam maupun luar negeri, agen perkapalan dan pelayaran samudera, angkutan udara, saat IPO hanya mengalami tingkat underpricing sebesar 0,047 dan PTPP bergerak di bidang pembangunan perumahan memiliki tingkat underpricing sebesar $0,018 \%$, lebih memercayai pengelolaan IPO oleh underwriter bergengsi. Ini berarti dapat disimpulkan bahwa, IPO yang dikelola oleh underwriter bergengsi menunjukkan underpricing yang lebih rendah.

\section{Pengaruh Reputasi Auditor Terhadap Underpricing}

Variabel non keuangan reputasi auditor terbukti berpengaruh signifikan positif pada tingkat underpricing. Temuan ini sejalan dengan penelitian Hoberg (2007), Beatty (1989), Kim, Krinsky and Jason Lee (1993). Hogan (1997) menemukan bahwa reputasi auditor yang baik akan mengurangi asimetri informasi sehingga tingkat underpricing rendah. Namun tidak sejalan dengan hasil penelitian penelitian Martani, Leony. Syahroza (2012) yang menyatakan bahwa reputasi auditor berpengaruh negatif terhadap underpricing.

Sesuai dengan kajian teori signaling yang menyatakan bahwa KAP besar merupakan pihak independen yang memberikan sinyal opini bebas andal daripada KAP kecil. Hal tersebut disebabkan karena auditor yang memiliki reputasi tinggi memiliki insentif lebih kecil untuk menghindari hal-hal yang dapat merusak reputasinya dibandingkan dengan auditor yang bereputasi rendah (Shockley, 1981). Jika laporan keuangan disajikan secara andal dan independen, maka laporan keuangan akan memiliki integritas yang tingi. Auditor yang mempunyai reputasi yang baik juga dapat dijadikan indikator tentang kualitas perusahaan yang melakukan IPO, karena auditor dengan 
reputasi yang baik tidak akan memberikan informasi yang keliru tentang perusahaan.

Dalam penelitian ini, terbukti beberapa perusahaan besar menggunakan jasa auditor yang professional seperti yang tergabung dalam the big four dengan harapan auditor yang bereputasi tinggi akan mempertahankan reputasinya dengan memberikan kualitas yang baik terhadap hasil auditannya. Sebagai contoh, TOWR (Sarana Menara Energy Tbk) yang bergerak di bidang jasa kecuali jasa di bidang hukum dan pajak dan melakukan investasi pada perusahaan lain menggunakan jasa auditor Purwanto, Suherman \& Surja yang merupakan mitra dari Ernst \& Young terbukti mengalami underpricing yang tinggi saat IPO yaitu sebesar 0,365. Ada hubungan positif antara return IPO masa lalu dan masa depan, penelitian ini juga menyimpulkan bahwa perusahaan IPO dengan underpricing yang lebih besar memiliki kualitas yang lebih baik .(Kaustia and Samuli, 2008). Jasa auditor yang professional akan mengurangi kesempatan emiten untuk berlaku curang dalam menyajikan informasi yang kurang akurat sehingga penggunaan auditor yang professional dapat digunakan sebagai petunjuk kualitas perusahaan.

\section{Pembahasan Variabel Yang Paling Dominan Terhadap Underpricing}

Variabel keuangan yang digunakan dalam penelitian ini yaitu DER, dan variabel non keuangan terdiri dari Underwriter, dan Auditor. Berdasarkan metode stepwise pada step 5 dalam tabel 4.11 didapatkan bahwa variabel non keuangan reputasi underwriter paling dominan memengaruhi underpricing. Reputasi Underwriter yang digunakan oleh perusahaan yang memiliki reputasi yang baik akan berpengaruh terhadap informasi yang akan diberikan oleh underwriter kepada investor. Underwriter dengan reputasi yang baik akan cenderung memberikan informasi yang berkualitas agar tidak membahayakan reputasi baik yang sudah dimilikinya. Oleh karena itu, besarnya informasi asimetri yang mungkin muncul akan berkurang. Sehingga dapat disimpulkan bahwa sebagian besar investor dalam menanamkan modalnya pada saham perdana lebih memperhatikan informasi non akuntansi atau variabel non keuangan pada prospektus perusahaan.

\section{Kesimpulan}

a. Hasil analisis statistik menunjukkan bahwa besarnya kontribusi pengaruh variabel independen DER, reputasi underwriter, dan reputasi auditor terhadap variabel dependen underpricing tergolong sangat rendah.

b. Perusahaan yang menggunakan underwriter bereputasi tinggi atau auditor yang berafiliasi dengan the big four terbukti dapat mengurangi terjadinya underpricing. Variabel ini juga terbukti menjadi variabel yang paling dominan memengaruhi underpricing.

c. Dari enam variabel yang diuji, hanya dua variabel yang signifikan memengaruhi underpricing yaitu reputasi underwriter dan reputasi auditor. Jadi dapat disimpulkan, investor dalam menginvestasikan dananya lebih memerhatikan variabel non keuangan atau informasi non akuntansi dari prospektus perusahaan.

\section{Saran}

a. Peneliti selanjutnya juga dapat memilih variabel-variabel independen lain yang diduga dapat mempengaruhi underpricing. Hal ini dikarenakan nilai koefisien determinasi (adjusted R2) yang rendah dalam penelitian ini menunjukkan 
kemampuan variabel-variabel independen yang dipilih dalam menjelaskan variabel dependen amat terbatas. Peneliti selanjutnya juga dapat menggunakan menggunakan metode pengukuran variabel yang berbeda, seperti untuk variabel ukuran perusahaan dapat digunakan total penjualan sebagai ukurannya, atau menggunakan sampel yang lebih spesifik pada sektor tertentu misalnya difokuskan hanya untuk sector manufaktur saja.

b. Bagi investor yang ingin melakukan investasi pada perusahaan yang melakukan IPO, sebaiknya mempertimbangkan faktor-faktor yang telah terbukti mempengaruhi tingkat underpricing yaitu reputasi underwriter dan reputasi auditor. Dengan demikian diharapkan dapat mengoptimalkan keuntungan (return) yang diperoleh dan meminimalkan risiko atas investasi yang dilakukan.

c. Bagi emiten yang akan melaksanakan IPO, disarankan untuk menggunakan jasa auditor dan underwriter yang bereputasi baik karena reputasinya yang baik meningkatkan kepercayaan calon investor sehingga menarik minat beli terhadap saham yang diperdagangkan.

\section{Referensi}

Balvers, R. Mc Donald dan R.E. Miller. 1988. Underpricing of New Issues and the Choice of Auditor as a Signal of Investment Banker Reputation. The Accounting Review. Vol. 63, pp. 602-622

Bapepam. 2012. Keputusan Ketua Badan Pengawas Pasar Modal, No: kep-347/BL/2012 Tanggal 1 Agustus 2012 tentang Kewajiban Penyajian dan Pengungkapan Laporan Tahunan bagi Emiten atau Perusahaan Publik.

Baron, D.P, 1982. A Model of The Demand for Investment Bank Advising and Distribution Services for New Issues. Journal of Finance.Vol. 45. pp. 955 - 976

Beatty, R. 1989. Auditor reputation and the pricing of initial public offerings, The Accounting Review, Vol. 64, No. 4. pp. 693-707.

Blake, D. \& Freris, A.F. 1997.The short run performance of initial public offerings: New results using a dynamic beta model. Advances in Pacific Basin Financial Markets 3:1189 - 1210.Disunting oleh T.Bos \& T.Fetherston. Connecticut: JAI Press.

Brigham, E. F. dan Houston, J. F. 2014.Dasar-Dasar Manajemen Keuangan.Jakarta :Erlangga.

Carter, Richard and Steven Manaster. 1990. Initial Public Offering and Underwriter Reputation. Journal of Financial.Vol 45. pp 1045-1067.

Chiraphadhanakul, Vichakorn, and Kennedy D.Gunawan. 2005. The Factors Affecting on IPO Return in Thai Stock Market. Proceeding of the International Conference Computer and Industrial Management, ICIM. Bangkok, Thailand. Vol. 13, No.SP 2. pp. $191-196$ 
Dawson, S.M. 1987. Secondary stock market performance of initial public offerings, Hong Kong, Singapore and Malaysia: 1978 - 1984Journal of Business Finance and Accounting. Vol. 14, pp. $65-76$.

Dimovski, William and Robert Brooks. 2008. The Underpricing of Gold Mining Initial Public Offerings. Research in International Business andFinance, Vol 22, No.1. pp 116.

Ghosh, C., R. Nag., and C.F. Sirmans. 2000. A Test of Signaling Value of IPO Underpricing with REIT IPO-SEO Pairs. Journal of Real Estate and Economics.Vol. 20. pp. 137154.

Ghozali, I. 2011, Aplikasi Analisis Multivariate dengan Program SPSS, Badan Penerbit Universitas Diponegoro, Semarang.

Hoberg, G. 2007. The Underwriter Persistence Phenomenon.Journal of Finance. Vol. 62, pp. 1169 - 1206.

Hogan, C.E. 1997. Cost and Benefits of Audit Quality in The IPO Market: A Self Selection Analysis. The Accounting Review.Vol. 72, No. 1. pp. 67-86.

How, Janice C.Y. Izan H.Y. and Monroe Gary S. 1995. Differential Information and The Underpricing of Initial Public Offerings: Australian Evidence. Journal of Accounting and Finance.Vol. 3. pp. 87 - 105

Jhonson, William. 2011. Underpricing and Underwriter Wealth Gains. Investment Management and Financial Innovations, USA.Vol. 8, pp. $45-63$.

Kasmir. 2014. Analisis Laporan Keuangan (1 ${ }^{\text {st }}$ ed.). Jakarta: Rajawali Pers.

Kim Jeong Bon, Itzhak Krinsky and Jason Lee. 1993. Motives for Going Public and Underpricing: New Findings from Korea. Journal of Business Financial and Accounting.Vol. 20.pp. 195 - 211.

Kunz, R. M., \& Aggarwal, R. 1994. Why initial public offerings are underpriced: Evidence from Switzerland. Journal of Banking \& Finance, Vol.18, pp. 705-723.

Ljungqvist, Alexander. 2005. IPO Underpricing. Handbook of Corporate Finance: Empirical Corporate Finance. The Journal of Finance, Vol. 2, pp. $375-422$

Martani, D., Sinaga Leony. I., and Syahroza, A. 2012.Analysis on Factors Affecting IPO Underpricing and their Effects on Earning Persistence.World Review of Business Research, Vol. 2.No. 2. pp. 1 - 15.

Ritter, J. R. 1984. The Hot Issue Market of 1980.Journal of Business, Vol. 54, pp . 215 240. 
Ritter, J.R. 1991, The Long-Run Performance of Initial Public Offerings. The Journal of Finance, March, Vol. XLVI, No. 1, pp. 3-27.

Ross, A. Steven. 1977. The Determination of Financial Structure: The Incentive Signaling Approach. Bell Journal of Economic Vol. 8, No. 1, pp. 23-40.

Shamsher Mohamad, Annuar Md. Nasir and Mohamed Arif. 1993. Analysis of underpricing in the Malaysian new issues market during 1975 - 1990: Are new issue excessively underpriced. Capital Market Review ,pp. 17 - 28.

Shockley, R. A. 1981. Perceptions of Auditor's Independence; An empirical analysis.The Accounting Reviews, Vol. 56, pp. 785-800.

Su, Dongwei and Belton M. Fleisher. 1997. Risk, Return and Regulation in Chinese stock Market. Journal of Economics and Business.Vol. 50. pp. 239 - 256

Thornton et al. 2009. Do Underwriters Create Value in the Determination of the IPO Final Offering Price?.The Journal of Applied Business Research.Vol. 25. pp. 1 - 11.

Undang-undang Republik Indonesia No. 8/ 1995. Pasar Modal

Welch, I. 1989. Seasoned Offerings, Imitation Costs, and The Underpricing of Initial Public Offerings. Journal of Finance. Vo. XLIV No.2, pp. 421-449. 